Article

\title{
Gamification Approaches for Education and Engagement on Pro-Environmental Behaviors: Searching for Best Practices
}

\author{
Tania Ouariachi * ${ }^{(}$, Chih-Yen Li and Wim J. L. Elving \\ Professorship Communication, Behaviour \& the Sustainable Society, EnTranCe, Center of Expertise Energy, \\ Hanze University of Applied Sciences, Zernikeplein 7, 9747 AS Groningen, The Netherlands; \\ yen32754@gmail.com (C.-Y.L.); w.j.l.elving@pl.hanze.nl (W.J.L.E.) \\ * Correspondence: t.ouariachi.peralta@pl.hanze.nl
}

Received: 22 March 2020; Accepted: 1 June 2020; Published: 3 June 2020

check for updates

\begin{abstract}
Education is a key factor to respond to the threat of climate change, increasing not only knowledge but also encouraging changes in attitudes and behaviors to adopt sustainable lifestyles. Scholars and practitioners in the field of education call for innovative ways of engaging youth - a reason why gamification has gained more attention in recent years. This paper aims at exploring the role of gamification in affecting pro-environmental behavioral change and searching for best practices for educational purposes. For that aim, pro-environmental gamification platforms are identified and analyzed by applying two different frameworks: the Octalysis Framework and the Climate Change Engagement through Games Framework. After scanning 181 cases, a final sample of six is analyzed and two of them are selected as best practices with higher potential to engage users in pro-environmental behavioral change: SaveOhno and JouleBug. Meaning, ownership, and social influence, as well as achievability, challenge, and credibility, are seen as core elements that can increase the success of gamification platforms. In conclusion, the more attributes are enclosed in the gamification design, the stronger physical and mental connections it builds up with participants. Insights from this study can help educators to select best practices and gamification designers to better influence behavioral change through game mechanics.
\end{abstract}

Keywords: gamification; games; behavior change; education; engagement; motivation; climate change

\section{Introduction}

Early in the late 19th century, scientists already gave a warning about the emission of carbon dioxide, saying it might lead to global warming. However, due to the actions of deniers and skeptics as well as economically oriented policies, the warning has not always been taken seriously enough and the concentration of the greenhouse gas has been continuously rising [1]. Effective climate change policy relies on the public's support and understanding; those who are aware of or cognitive of experiencing climate change are key supporters of climate policy [2]. Since climate change is a global issue and cannot be solved by a single person; it is necessary to expand awareness and empower people to deal with this topic [1]. However, raising awareness of environmental issues is just the beginning. Governments, communication and education specialists, and environmental activists are suggesting taking a further step, beyond raising awareness and knowledge, to encouraging people to change behaviors to mitigate the stress of the earth. Eisenack [3] suggests existing communication and education processes should be improved to engage people in developing suitable environmental solutions.

In search of innovative and interactive ways to educate and engage citizens, especially young people, the use of gamification has gained the attention of scholars and practitioners in recent years. 
While serious games (games the purpose of which exceeds entertainment) mostly aim at raising awareness of "serious" issues, gamification (the application of game-design elements in non-game contexts) is seen as a strategy that can positively engage people in behavioral change [4-7]. The use of gamification in education has been applied to formal, non-formal and informal education settings. However, academia knows little about how gamification works with environmental topics, what its characteristics and actual performance is, or how much potential it has to create engagement.

This paper aims at exploring the role of gamification in affecting pro-environmental behavioral change and searching for best practices for educational purposes. For that aim, gamification platforms were identified by conducting a literature review and web search and analyzed by conducting a qualitative analysis using two different frameworks, which will be further described in the next section.

\section{A New Education Paradigm: From Information Exposure to Action}

Learning to build a better planet than today's requires a holistic approach. In recent years, we have seen a shift in climate and environmental education from exposure to information to transformation of values and behaviors in order to contribute to solutions for environmental problems and, by extension, to the creation of a sustainable society. A more modern pedagogy creates a process that encourages "concrete action" by stimulating interest, understanding, and participation. This participatory approach values experience and feeling as part of a process of experimentation, not just relaying of knowledge. Promoting equitable, inclusive, and fair societies requires creating processes for citizen participation that imply "shared decision-making" and an assumption of responsibilities in favor of global sustainability [8,9].

Different models have been developed by scholars trying to explain this new paradigm. For instance, Cantell et al. [10] proposes the "bicycle model", a holistic approach to climate change education that emphasizes the importance of different factors: knowledge, thinking skills, values, identity, worldview, action, motivation, participation, future orientation, hope and other emotions, and operational barriers. Monroe et al. [11] conducted a systematic review (959 unique citation records) to describe effective educational strategies in formal and non-formal settings. The study highlighted two effective strategies: (1) focusing on personally relevant and meaningful information and (2) using interactive and engaging teaching methods. Regarding the second strategy, interventions include experiential, inquiry-based, and constructivist methods, including gamification, role-plays and simulations that mimic reality.

Visual images play an important role in this type of strategy. Manzo [12] emphasizes the power of the influences that images have, and how images are a double-edged sword in changing people's attitude. For instance, an image of a hungry polar bear might raise climate change awareness and stimulate sympathy to call for behaving in environmentally friendly ways and raising funds; on the other hand, people might get tired of being flooded with polar bears and climate change-related images and turn their back on them. In this case, enhancing a better understanding of environmental issues does not necessarily mean that people will change their behaviors and perform in the expected ways [13].

\section{Gamification and Behavioral Change}

In 2011, Deterding et al. [14] (pp. 9-15) define gamification as "the use of game design elements in non-game contexts". In response to Deterding et al.'s definition of gamification, other authors like Werbach [15] (p. 266) redefine the concept into "the process of making activities more game-like", proclaiming that not every non-game context that includes game design elements ais considered to be gamified. Instead, gamification is a combination of the game elements' selection, application, implementation, and integration to improve users' experience, bringing it closer to typical fun and interesting gameplay experience. In 2016, Mazur-Stommen and Farley [5] (pp. 19-24) included behavior change in the definition of gamification. From their perspective, gamification is the process whereby designers incorporate game mechanics into everyday activities to provide added motivation 
for behavior change. Essentially, from this perspective, gamification is seen as "approaching problems to tap into the psychology of motivation".

Motivations that lead to behavior change can be divided into extrinsic and intrinsic factors. Extrinsic motivation relies on external stimulation to change the behavior, while intrinsic motivation is driven by oneself [16]. Grossberg et al. [17] state that the points, badges and leaderboards (PBL) system provides clear and immediate rewards to players and is a powerful motivator to change players' behaviors. By comparing performance records with peer members, players increase their sense of achievement and are more likely to maintain or improve their current behaviors. However, players might also get demotivated when the personal score is fallen behind the record too much [18].

In 2017, Sailer et al. [19] suggest not only visible game elements such as points, badges, leaderboards, performance graphs, meaningful stories, avatars, and teammates should be considered, but also players' need of psychological satisfaction, including the need for competence, autonomy, and social relatedness should be included during the design of gamification tools. Since climate change is a long-term global issue, the potential adaptation and mitigation solutions should be able to drive eco-friendly acts long and support by governmental policy, therefore intrinsic motivation should become a major concern [16] (pp. 758-763). In 2014, Conway [20] states that those gamification designs that only focus on extrinsic rewarding systems but failed to acknowledge the users' psychological needs are supposed to be named "zombification" because users are assumed to perform routinely in the same way. Other authors like Chou [18] defend that the idealistic behavior change strategy is a combination of extrinsic motivating policies and intrinsic persuasion because, if only extrinsic motivation is taken into account, once the rewarding system stops, the users' motivation will decrease due to the feeling of being "betrayed" (pp. 342-344).

Gamification has been widely applied in many contexts, such as the education, government, health, marketing, and management fields. In the field of the environment, game designers have developed green games or added green elements to non-game contexts to encourage pro-environmental action [21].

\section{Theoretical Frameworks}

Gamification theories at the early stage focus on giving definitions and examining existing cases $[14,15,17,19]$. Researchers aim to check whether gamification is worthy to name as a new and future trending technique or just an old marketing strategy with new packaging. Later, scholars mainly put emphasis on the use of game elements and discuss motivations [17,22]. The following theoretical frameworks provide a comprehensive vision of which factors should be considered to motivate people into action and on how to evaluate designs.

\subsection{Octalysis Framework}

The Octalysis Framework, developed by Chou [18], focuses mainly on motivation as well as human-centered design, explaining the function and potential outcomes of motivational design. With inspiration from Fogg [23]'s B=MAP motivation model developed in 2003 (a behavior change model that drives motivation, ability and prompts core values), the framework is based on eight mental core drives to explain the motivation behind each human behavior: Epic Meaning and Calling, Development and Accomplishment, Empowerment of Creativity and Feedback, Ownership and Possession, Social Influence and Relatedness, Scarcity and Impatience, Unpredictability and Curiosity, and Loss and Avoidance.

Epic Meaning and Calling refers to a person's belief that he or she is doing something greater than themself, or those who believe they have "beginner's luck". Development and Accomplishment is related to the practice of points, badges and leader board systems. Empowerment of Creativity and Feedback is a key factor in the Octalysis Framework because it inspires long-term positive emotions and an emphasis on intrinsic motivation. The author believes that by nature we are creative beings, and we yearn to imagine and invent in creative processes where the journey in of itself brings happiness. 
When a user can continuously use creativity, the game designer no longer needs to constantly create new content to make things engaging. Those talents need to be rewarded to be further developed. However, this core drive is also the hardest to implement correctly. Ownership and Possession refers to the feelings of owning or having strong connections to something they are willing to improve. It is related to elements such as virtual goods and virtual currencies; it makes us want to accumulate wealth. Social Influence and Relatedness connects to activities inspired by what other people think, do, or say, and themes like mentorship, competition, envy, group quests, social treasures and companionship. The "relatedness" part deals with things like attachment to emotional associations and the feeling of nostalgia. When this core driver is used correctly, it promotes strong and long-lasting motivations to become engaged. Scarcity and Impatience refers to a desire of wanting something or waiting to get something. The anxiety lasts until the goal is achieved or given up. Unpredictability and Curiosity is the main force behind our desire with experiences that are uncertain and involve chance, which makes people feel excited. Finally, Loss and Avoidance mmotivates users through the fear of losing something or having undesirable events transpire. According to Chou [18], all human behaviours are driven by at least one motivator or more.

Chou [18] further refines the core drives and categorizes them into two categories. a) White hat motivators (Epic Meaning and Calling, Development and Accomplishment, Empowerment of Creativity and Feedback, Ownership and Possession, and Social influence and Relatedness) vs. black hat motivators (Scarcity and Impatience, Unpredictability and Curiosity, and Loss and Avoidance). This categorization separates the gamification users' emotional engagement into positive and negative. Black hat motivators make us feel anxious but they can create an urgent need to stimulate users to perform certain actions, even though people might not appreciate those negative feelings. b) Left-brain motivators (Development and Accomplishment, Ownership and Possession, and Scarcity and Impatience) vs. right-brain motivators (Empowerment of Creativity and Feedback, Social Influence and Relatedness, and Unpredictability and Curiosity). It divides human motivations into extrinsic or intrinsic-driven. The left brain represents logic, ownership, and analytical thought, while the right brain relates to creativity, sociality, and curiosity, which can create longer engagement.

\subsection{Climate Change Engagement through Games Framework}

Ouariachi et al. [24] propose a set of game attributes that could maximize the cognitive, emotional, and behavioral engagement of players, using semi-structured interviews with experts to identify a set of game attributes and a group discussion with teenagers to validate them. By applying grounded theory, they have developed a framework for climate change engagement through games. The framework consists of 15 key game attributes classified in three dimensions:

1. Cognitive involvement: what people think and know, and how many mental efforts they are willing to make. These are credible, experiential learning, concrete, challenging, leveling-up, fun, achievable, feedback-oriented, meaningful, narrative-driven, simulating.

2. Emotional involvement: what and how strongly people feel about climate change. These are identity-driven, concrete, challenging, efficacy-enhancing, reward-driven, achievable, feedback-oriented, meaningful, narrative-driven, simulating.

3. Behavioral involvement: what and how much people do to address climate change. These are social, efficacy-enhancing, reward-driven, leveling up, fun, achievable, feedback-oriented, meaningful, narrative-driven, simulating.

The framework suggests that serious games or gamification platforms that contain these attributes will enhance their potential to cognitively, emotionally, and/or behaviorally engage people in climate-change-related issues. Some of the 15 game attributes fall into the three dimensions, which means that they are core elements to maximize the potential of cognitive, emotional and behavioral involvement simultaneously. These are achievable, feedback-oriented, meaningful, narrative-driven and simulating. Other attributes fall into two categories. 
According to Ouariachi et al. [24], ideally, in order to create inspiring tools, there is a need to appeal, not only to the analytical processing system, but to the overall experiential system, playing with reality, highlighting powerful narratives that connect with people's values and experiences, and paying careful attention to both verbal, written and audio-visual communication. An engaging experience should also be fun, let the players work hard towards clear goals and make them feel good. When these factors are mixed with social interaction and peer pressure, there is more chance that actions will take place and a social movement will be created.

\section{Materials and Methods}

Since the role of gamification in affecting pro-environmental behavioral change is a relatively new topic, this exploratory study makes use of qualitative research methods. Exploratory studies aim to discover underlying issues, seek new insights, and evaluate the phenomenon from different angles $[25,26]$. Triangulation is theoretically applied by using different models, and methodologically applied by using two types of secondary data analysis and qualitative content analysis. As with exploratory studies, triangulation is often practiced to study little-explored or non-explored research topics $[27,28]$. Two different stages can be distinguished in the study:

First stage: identification and selection. To identify pro-environmental gamification platforms, a literature review was carried out in Scopus and Google Scholar, as well as a web search in the main search engines using the following keywords: (climate change/ global warming/ environment/ sustainability) and (communication/ education/ behavior) and (gamification/ gamified system/ gamifying/ game elements) in both English and Mandarin, the working languages of the researchers. A total of 181 cases were identified and further scanned by interacting with them. Then, a final sample of six was selected based on a) topics related to pro-environmental behavioral change, $b$ ) potential to be used as an educational tool (on the basis of learning, and on the possibilities to be implemented in class, individually or in groups), c) accessibility online and for free (to address possible economic restrictions or difficulties from users to access gamified experiences), and d) availability in English and/or Mandarin (the languages of the authors). The six final platforms were Consumption of Daily Life [29], Oroeco [30], SaveOhno [31], Recyclebank [32], JouleBug [33], and My Little Plastic Footprint [34].

Second stage: qualitative content analysis. To analyze the selected cases, first of all, the Octalysis framework [18] was applied via an online tool where two researchers can provide scores to the eight different drivers and fill each empty section (Figure 1). Every core drive was evaluated from 0-10. Points from each motivator were squared and summed to get the final score. After the evaluation, the tool provided comments in the bottom left section for users to double-check the potential of the designs [35].

Secondly, another round of analysis was carried out by applying the Climate Change Engagement through Games Framework [24] to further explore the potential of these cases in motivating pro-environmental behavior change. In this case, researchers opt for qualitative content analysis as an approach to code data. Qualitative content analysis focuses on manifest and latent features, entailing quantification by coding frequencies to detect patterns in the data. In this type of research, the emphasis is on achieving consistency of interpretation by having several researchers for coding; the intercoder reliability shows therefore to what extent different coders agree on the coding of the same material. In this case, two researchers use a checklist to mark the presence or not of the different game attributes, sharing a protocol with guidelines to fill in the checklist. Despite the subjectivity of some of the criteria and the interpretative implications, both researchers agreed on all features and there was no need to solve discrepancies. No previous training was necessary. Trustworthiness (credibility, transferability, dependability and confirmability) is proposed in qualitative content analysis as a means to ensure quality and methodological soundness $[24,36]$. 


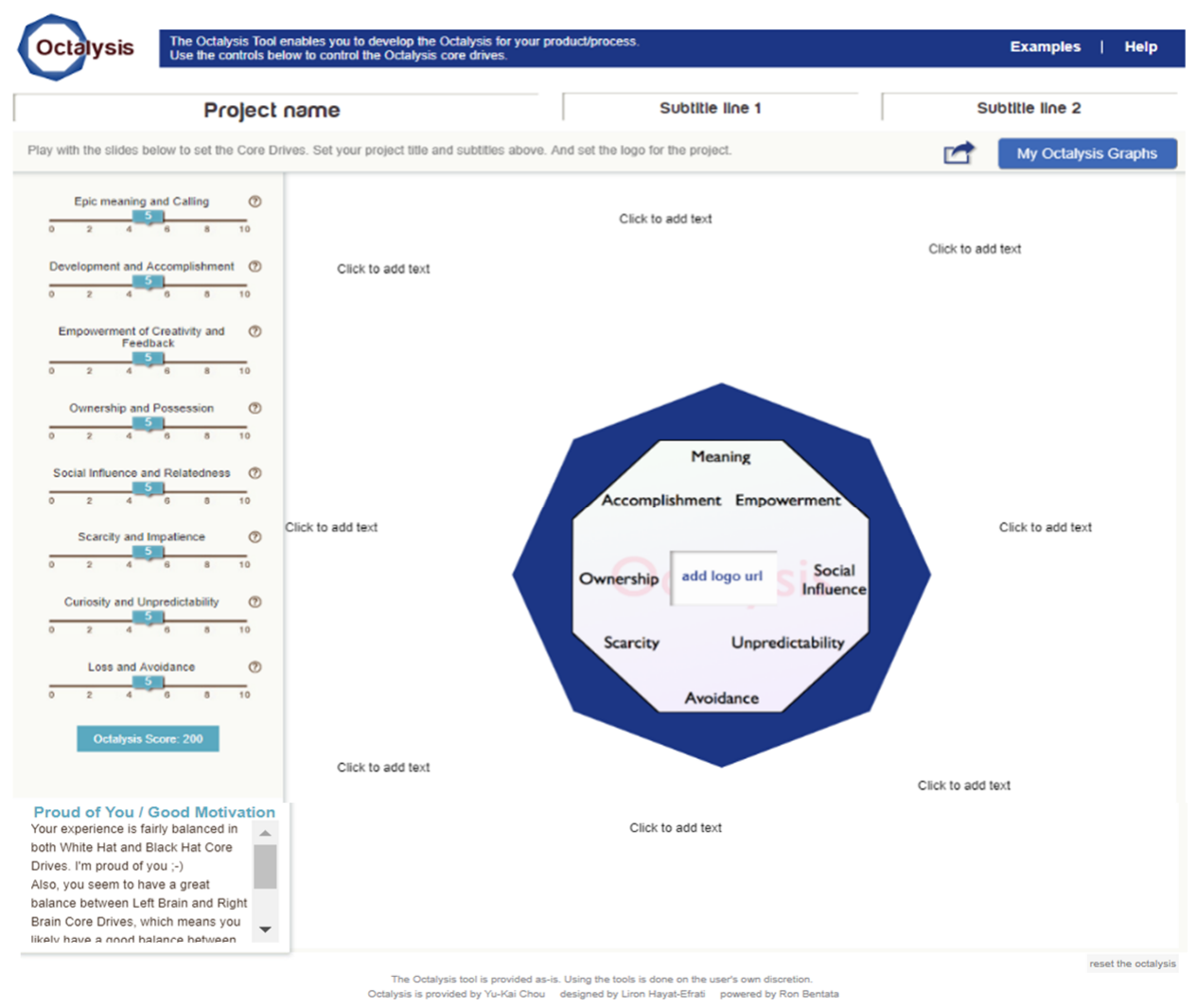

Figure 1. The Octalysis Tool [35].

The integration of two different models in this second stage of qualitative content analysis relies on the need for 1) adding theoretical triangulation in exploratory studies and 2) integrating the strengths of each model. Both models follow the same goal; however, while the first focuses mostly on gamification as the tool, the second one focuses on climate-change-related issues as the main topic.

\section{Results}

One of the first observations was that gamification platforms with an educational purpose are quite popular, especially digital ones and on mobile devices. They are usually used for promoting behavioral change but also to raise awareness of certain topics, including formats such as simulations, strategic games and news games. Competition is quite a recurrent strategy, and energy saving and efficiency are two of the most popular pro-environmental behaviors promoted, alongside waste management and recycling. Topics are generally concerned with people's daily lives, including individuals' financial considerations and desire to live environmentally friendly lives, but also travelling behaviors. Developers include commercial, charitable, educational and governmental organizations.

\subsection{Application of Octalysis Framework}

According to the design of the Octalysis framework [18], the scoring system is the sum of the square number of each core motivation. If every core drive is fully applied, the highest score will be 800 points $\left(10^{2 * 8}\right)$. Yet, only the well-known dominant gamified designs can receive up to 8 or 9 points on specific core drive(s), as stated by Chou [18]. In addition, he states that, based on the design types, a serious game design might score above 350 points, while a gamification platform ranks less than 150 points, and function-oriented design not considering any human-centered designs can only rate less than 50 points. The following analysis also checked the referring tips on the website in case of interpretation errors [35].

Below is the analysis of the final six selected cases: 
1. Consumption of Daily Life (score: <50): this aims to search for "power-eating monsters" at home through a webpage gamified calculator developed by the Industrial Technology Research Institute in Taiwan in 2018 [29]. It has been developed to provide trustworthy measurement for households, containing diagnosis, results and solutions for electricity performance. By providing a comparison between different electronic devices and with other households, the energy-saving recommendations keep the public from producing a great amount of electricity during peak hours. Core drivers: users are requested to fill in detailed information about their electronic devices, provoking an increase in the feeling of Ownership and Possession. Regarding the Epic Meaning and Calling driver, users are named as human heroes to beat down the electricity beasts and solve energy shortage issues. By comparing a household's energy performance with the average records, together with allowing a person to share one's electricity percentage on social media, individuals receive peer pressure driven by Social Influence and Relatedness. However, it seems that the application focuses mainly on the Loss and Avoidance core drive to persuade households to upgrade their power-driven appliances. People indeed prefer to pay the bill smartly. In avoidance of losing extra money, users with an eco-friendly mindset have the possibility to purchase energy-saving products, but, if the current appliance works functionally and users are not confident with new settings, the Loss and Avoidance factor could work oppositely.

2. Recyclebank (score: <50): an online gamified platform allowing visitors to earn points from reading articles, doing small tests, recycling and playing small games to enhance climate change-related knowledge. Users exchange recycling and waste-reusing experiences with others to collect points and purchase green products using those points [32]. Points work as a rewarding system to encourage visitors to collect and spend points on the platform frequently. The membership of Recyclebank allows users to purchase eco-friendly products or visit partner business with a discount. Core drivers: the platform applies Epic Meaning and Calling, Empowerment of Creativity and Feedback, Ownership and Possession, and Social Influence and Relatedness. The call for sharing waste-reusing and recycling ideas, acting green, and buying environment-friendly products convinces users that their efforts are meaningful. People provide recycling tips as well as waste-utilizing ideas to exchange instant feedback and comments with other users. Each post gives the individual a sense of ownership so that users stick to the platform and frequently check every latest interaction. Simultaneously, people build up a social network and influence one another on the platform. However, the commercial-oriented rewarding system, as well as scarce exclusive discounts, could decreases the users' feeling of doing meaningful work and intentions of modifying behavior. Therefore, there is unbalance between intrinsic and extrinsic motivation drivers.

3. My Little Plastic Footprint (score: 50 100): operated by Plastic Soup Foundation and support by the $\mathrm{UN}$, this application aims to call the public to stop using plastic products and reduce ocean pollution waste [34]. Participants are seen as heroes and encouraged to collaborate with other plastic champions to fight against plastic and ocean pollution. Core drivers: Epic Meaning and Calling is one of the main drivers. Developers also include Ownership and Possession, Social Influence and Relatedness, and Loss and Avoidance core drives in the design but place less attention on Development and Accomplishment, Empowerment of Creativity and Feedback, and Scarcity and Impatience motivation. Players receive challenges from ocean-pollution-related multiple choice questions to earn points, unlock ocean milestones, and collect junk art creations to enhance the sense of accomplishment. By answering questions, signing up to campaigns, sharing environmental solutions, or publishing plastic waste-reducing announcements, participants are empowered to give benefit to the earth in their preferred way. The art gallery collection, posting ideas, and the intention to maintain a personal image consisting of behavior change announcements increase the users' ownership feeling. Social influences also play an important role in supervising a participants' behavior, preventing them from quitting, and influencing others to modify their living styles. However, the application begins by asking visitors to register their email accounts, 
publish an announcement, and share "like" comments on social media when they are new to the program. This might bring the risk of decreasing the users' trust. In addition, participants can only provide pollution and waste suggestions and press "like/agree" to others' statements but are unable to exchange feedback with one another.

4. Oroeco (score: 50 100): this is a gamified website and mobile application platform developed by Oroeco and the University of California, Berkeley [30]. The application records an individual's daily behavior and checks one's carbon value monthly and yearly. Users are encouraged to behave in environment-friendly ways and purchase green products. There are a few studies associated with this case [17,21]. Core drivers: the main focus is on Development and Accomplishment, Empowerment, Creativity and Feedback, and Ownership and Possession. Epic Meaning and Calling, as well as Social Influence and Relatedness, are also included in the design. Oroeco empowers participants with instant feedback, as well as multiple quests, scoreboards, and batches, so that people can perform their preferred actions to do meaningful environmental improvements. Users collect virtual currency by updating their proactive eco-friendly behavior achievements and sharing carbon-eliminating tips. A set of batches of collection and experience-sharing posts increase the owners' pride and social influence on the gamification platform. In this case, white hat gamification receives greater attention, while black hat motivations such as Scarcity and Impatience, Unpredictability and Curiosity, and Loss and Avoidance, which can stimulate an instant response, are avoided. Oroeceo highly relies on participants' "voluntary" act. Once users get hooked by another gamified design or other appealing topics, they might leave the platform.

5. SaveOhno (score: 100 150): this first appeared on Kickstarter to raise funds [37]. Within five years, it became an influencing social venture institute focusing on climate-change-related works and engaging the public with behavior change [31,37]. This online platform gathers environmental activists to deliver messages, raise funds, and encourage visitors to sign up petitions. Core drivers: Epic Meaning and Calling and Social Influence and Relatedness are the strongest drivers. By addressing participants as environmental activists and heroes of the virtual family members, people understand the influence of their actions. When clicking on the "sign for the petition" button, participants follow the trend to save the earth and natural species. By deciding whether other users' eco-friendly actions are meaningful, receiving followers or participating in group campaigns, players are empowered as social influencers to affect the others on the platform. Development and Accomplishment, Empowerment of Creativity and Feedback, and Ownership and Possession core drives are also applied. Users own the right to engage with environmental concerns in multiple ways and can feel the sense of accomplishment via fund-raising, petition-signing, and gaining fans' strategies. SaveOhno creates a virtual character coming from the next century, who writes emails to players to keep them active in visiting the platform. Therefore, this case focuses on developing white hat core drives. Black hat gamification, such as via Scarcity and Impatience, Unpredictability and Curiosity, and Loss and Avoidance motivations, also receives attention, but less.

6. JouleBug (score: 100 150): this is a gamified mobile application aiming to engage users to behave in environment-friendly ways, as well as to develop a deeper connection between the local community and nature [33]. Unlike wearable devices that automatically record human behaviors, JouleBug participants need to actively click on the "buzz" button whenever they perform the desired actions to keep, record and collect points. Core drivers: Social Influence and Relatedness, Epic Meaning and Calling, and Development and Accomplishment are the three strongest core drives. The platform provides a follower/following system to encourage participants to actively update their achievements. Those who share the same values and interests can easily make links with each other. Users gain self-confidence, become more willing to join local challenges and get self-activated to do word-of-mouth communication when their social influence increases. Users can also accept taking extra actions or dealing with local challenges. Offering extra points 
to the beginners can ensure players to stay longer in the application. Loss and Avoidance and Scarcity and Impatience are used by providing limited opportunities and unique challenges to make the winner's record outstanding. Black hat motivations work when players participate in time-limited group challenges. The application provides multiple options for users to choose their desired behavior modifications. However, there is a lack of urgency. According to Chou [18], if there are only 3-5 options to select, the quests should last within a limited time to improve the player's engagement experience. This specific case seems to also find a balance between white and black hat motivations [35].

As observed in the cases above, the six selected gamification platforms apply different motivation elements based on the design purpose and its target audience. Based on the score range, the examined cases can be divided into three groups: two higher-quality, two medium-quality and two lower-quality (Table 1). The best gamification platforms not only focus mostly on white hat motivators (positive emotions) and find a balance between left-brain (extrinsic) and right-brain (intrinsic) core drives, but also include into their design black hat motivators (negative emotions). Left-brain and black hat core drives provide hooks to attract participants to exploring the gamification platforms within a short time and urgently encourage them to perform certain actions, while right-brain and white hat drives keep users staying longer and remaining positive in the platforms.

Table 1. Summary of scores.

\begin{tabular}{ccc}
\hline NAME & TOPIC & SCORE \\
\hline Consumption of Daily Life & Energy saving & $<50$ \\
Recyclebank & Waste management & $<50$ \\
My Little Plastic Footprint & Ocean waste pollution & $50 \sim 100$ \\
Oroeco & $\mathrm{CO}_{2}$ emissions and energy saving & $50 \sim 100$ \\
SaveOhno & Environmental activism & $100 \sim 150$ \\
JouleBug & Daily sustainable practices & $100 \sim 150$ \\
\hline
\end{tabular}

\subsection{Application of Climate Change Engagement through Games Framework}

After exploring how motivation core drives work in the six selected cases and examining how those motivators shape participant pro-environmental behavior, now we explore the capacity of these gamification platforms to engage participants at the cognitive, emotional and behavioral levels. A checklist based on the Climate Change Engagement through Games Framework [24] is applied to the six cases (Table 2).

Table 2. Checklist of game attributes.

\begin{tabular}{|c|c|c|c|c|c|c|}
\hline & $\begin{array}{l}\text { Consumption of } \\
\text { Daily Life }\end{array}$ & Oreoco & SaveOhno & Recyclebank & JouleBug & $\begin{array}{l}\text { My Little Plastic } \\
\text { Footprint }\end{array}$ \\
\hline Achievable & $\mathrm{y}$ & $\mathrm{y}$ & $\mathrm{y}$ & $\mathrm{y}$ & $\mathrm{y}$ & $\mathrm{y}$ \\
\hline Challenging & $\mathrm{y}$ & $\mathrm{y}$ & $\mathrm{y}$ & $\mathrm{y}$ & $\mathrm{y}$ & $\mathrm{y}$ \\
\hline Concrete & $\mathrm{y}$ & $\mathrm{y}$ & $\mathrm{y}$ & & $\mathrm{y}$ & \\
\hline Credibility & $\mathrm{y}$ & $\mathrm{y}$ & $\mathrm{y}$ & $\mathrm{y}$ & $\mathrm{y}$ & $\mathrm{y}$ \\
\hline Efficacy enhancing & $\mathrm{y}$ & & & & $\mathrm{y}$ & \\
\hline Experiential learning & & $\mathrm{y}$ & $\mathrm{y}$ & $\mathrm{y}$ & $\mathrm{y}$ & $\mathrm{y}$ \\
\hline Feedback oriented & $\mathrm{y}$ & $\mathrm{y}$ & $\mathrm{y}$ & $\mathrm{y}$ & $\mathrm{y}$ & $\mathrm{y}$ \\
\hline Fun & & & $\mathrm{y}$ & $\mathrm{y}$ & $\mathrm{y}$ & \\
\hline Identity-driven & & & $\mathrm{y}$ & & & \\
\hline Leveling-up & & & & & & \\
\hline Meaningful & & & & & & \\
\hline Narrative-driven & $\mathrm{y}$ & $\mathrm{y}$ & $\mathrm{y}$ & $\mathrm{y}$ & $\mathrm{y}$ & $\mathrm{y}$ \\
\hline Reward-driven & & & & $\mathrm{y}$ & $\mathrm{y}$ & \\
\hline Simulating & $\mathrm{y}$ & & $\mathrm{y}$ & & & \\
\hline Social & & $\mathrm{y}$ & $\mathrm{y}$ & $\mathrm{y}$ & $\mathrm{y}$ & $\mathrm{y}$ \\
\hline
\end{tabular}


The two gamification cases that scored higher through the Octalysis Framework [18], SaveOhno and JouleBug also enclose more game attributes from the Climate Change Engagement through Games Framework [24], which means that their potential is higher to engage players not only at the cognitive and emotional levels but also behavioral level. SaveOhno does not score in efficacy-enhancing, leveling-up, or reward-driven characteristics, yet all cognitive, emotional, and behavioral dimensions contain at least one attribute (Figure 2a). Findings indicate that SaveOhno has great potential to engage gamification participants cognitively, emotionally, and behaviorally. In other words, users are expected to engage in pro-environmental thoughts, feelings and actions. JouleBug, on the other hand, does not include identity-driven, leveling-up, narrative-driven, or simulating attributes, as Figure $2 \mathrm{~b}$ shows.

Figure 3 shows that there are five attributes applied in all six cases:

- Achievable: promoting possible actions within the reach of the individual.

- Challenging: a task that requires a certain degree of effort to perform.

- Credibility: trustworthy information and inspirations.

- Feedback-oriented: evaluation of current performance relative to a goal.

- Meaningful: evoking intense feelings.

These five attributes connect directly to the dimension of cognitive engagement according to the framework. In addition, from these attributes, challenging connects with the emotional dimension (working on raising public awareness together with emotional connections), while achievable, feedback-oriented, and meaningful connect with both the emotional and behavioral dimensions. The latest ones can be considered the most powerful because they fall into the three different categories but also social when we are aiming at behavioral change. In fact, the attribute social is found in five out of the six examples.

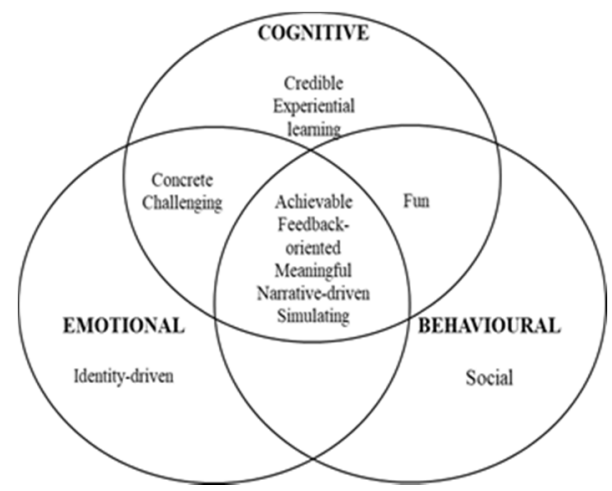

(a)

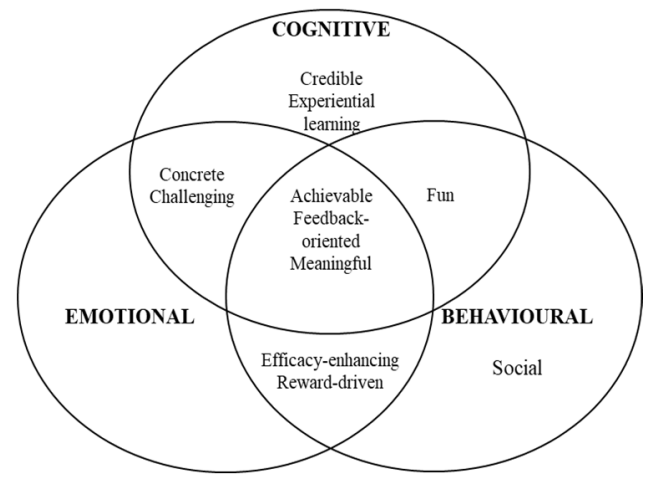

(b)

Figure 2. (a) SaveOhno's game attributes; (b) JouleBug's game attributes. 


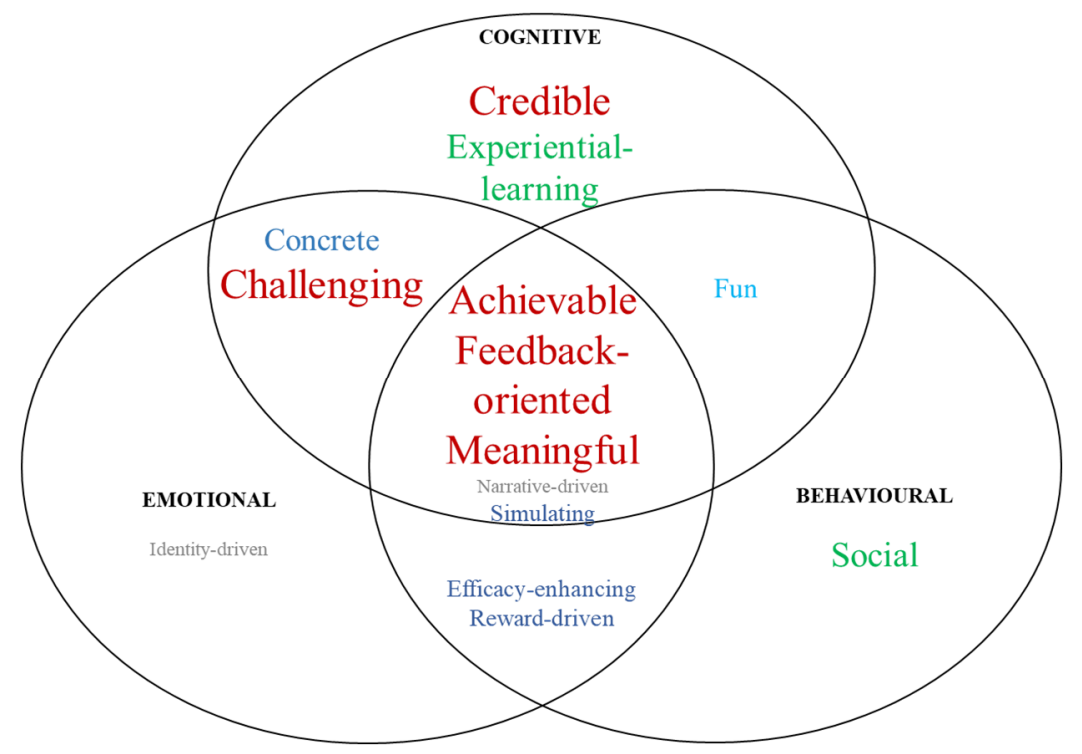

Figure 3. Summary of game attributes used by the six gamification practices, using a word cloud style.

\section{Discussion and Conclusions}

For a long time, scholars, practitioners and activists have mainly put the focus on delivering pro-environmental messages to the public [13]. Recently, the field of climate and environmental education have gone beyond transferring knowledge and values to also create a fluid process that encourages concrete actions by stimulating interest and nurturing participation. Providing design experiences where participants can learn through "doing and being" instead of just receiving information in a passive way can be very powerful, since first-hand experience is a "much better teacher" than exposure to information [38]. Gamification is a relatively new communication and education approach that aims at engaging citizens not just cognitively and emotionally but also behaviorally.

This study concludes that gamification approaches have potential to educate and encourage pro-environmental behavioral change, as long as they combine in their design extrinsic and intrinsic motivational elements, short-term and long-term drivers, and game attributes that encourage taking action in real life. Secondly, based on the application of two different frameworks, SaveOhno and JouleBug have scored higher as good practices with potential to engage users in behavioral change due to the powerful core drives and their well-balanced between extrinsic and intrinsic motivations. These platforms were chosen after analyzing six different gamification platforms, which met the selection criteria from a total of 181 climate change or sustainability-related platforms identified.

When looking at the core drivers from the Octalysis Framework, Epic Meaning and Calling, Ownership and Possession, and Social Influence and Relatedness are common core drives that have been practiced by all six gamification cases. The findings show that some gamification cases failed to find a balance between left-brain (extrinsic) and right-brain (intrinsic) motivators. In addition, climate change and sustainability gamification designs tend to have a preference for white hat motivators (positive feelings) to keep users' experience positive, but they often ignore black hat motivators (negative feelings), which, if designed properly and consciously, can encourage urgent behavior modification and balance users' emotions. Therefore, best practices find a balance in the use of positive and negative emotions, as well as extrinsic and intrinsic motivators. Regarding the Climate Change Engagement through Games Framework, game attributes such as Achievable, Challenging, Credible, Feedback-oriented, and Meaningful are seen as valuable to increase the potential to engage participants at the cognitive, emotional, and behavioral levels simultaneously. The analysis indicates that the more attributes are enclosed in the gamification design, the stronger physical and mental connections it builds-up with participants, and the greater the potential to influence human behavior. 
Regarding limitations, we acknowledge two types of limitations: methodological and personal. We recognize issues with sample and selection. The difficulty when selecting gamification platforms is related to the fact that there is a lack of a clear and united definition of gamification. Lines can be blurred between gamification and serious games, simulations and playful designs $[14,15,39]$. The linguistic limitations of the authors (only in English and/or Mandarin) also have an impact when identifying gamification cases that could act as best practices. When collecting data and interpreting results, it is important to acknowledge subjectivity and interpretative implications, despite the effort to achieve reliability and validity in the analysis. In addition, there is a lack of previous studies on this very specific field.

Insights from this study can help educators to select best practices, and gamification designers to better influence behavioral change through game elements. The practice of the Octalysis framework as well as the Climate Change Engagement through Games Framework can also provide insights for scholars by providing evaluation standards for climate- and sustainability-related gamification platforms. Future academic studies are recommended to test the applicability of the Octalysis Framework and the Climate Change Engagement through Game Framework in predicting pro-environmental engagement. Academics are encouraged to apply these frameworks with other cases and to carry out empirical study to evaluate if the selected best practices indeed have the potential to influence human behavior in the short and long term.

Author Contributions: Conceptualization, T.O., C.-Y.L. and W.J.L.E.; methodology, T.O. and C.-Y.L.; formal analysis, C.-Y.L.; data validation, T.O.; writing-original draft preparation, C.Y.L.; writing-review, T.O. and W.J.L.E.; supervision, T.O. and W.J.L.E. All authors have read and agreed to the published version of the manuscript.

Funding: This research received no external funding.

Conflicts of Interest: The authors declare no conflict of interest.

\section{References}

1. Eisenack, K.; Reckien, D. Climate Change and Simulation /Gaming. Simul. Gaming 2013, 44, $245-252$. [CrossRef]

2. Rhodes, E.; Axsen, J.; Jaccard, M. Exploring Citizen Support for Different Types of Climate Policy. Ecol. Econ. 2017, 137, 56-69. [CrossRef]

3. Eisenack, K. A Climate Change Board Game for Interdisciplinary Communication and Education. Simul. Gaming 2012, 44, 328-348. [CrossRef]

4. Hamari, J.; Koivisto, J.; Sarsa, H. Does Gamification Work?-A Literature Review of Empirical Studies on Gamification. In Proceedings of the 2014 47th Hawaii International Conference on System Sciences, Waikoloa, HI, USA, 6-9 January 2014; pp. 3025-3034.

5. Mazur-Stommen, S.; Farley, K. Games for Grownups: The Role of Gamification in Climate Change and Sustainability; Indicia Consulting LLC: Washington, DC, USA, 2016.

6. Johnson, D.; Horton, E.; Mulcahy, R.F.; Foth, M. Gamification and serious games within the domain of domestic energy consumption: A systematic review. Renew. Sustain. Energy Rev. 2017, 73, 249-264. [CrossRef]

7. Wee, S.-C.; Choong, W.W. Gamification: Predicting the effectiveness of variety game design elements to intrinsically motivate users' energy conservation behaviour. J. Environ. Manag. 2019, 233, 97-106. [CrossRef]

8. Gutierrez-Pérez, J. Contemporary epistemological advances in the field of environmental education. REMEA 2016, 33, 83-94.

9. Heras Hernández, F. A participacion como proceso de aprendizaxe e conecemento social. Ambient. Sustentable 2006, 1-2, 229-242.

10. Cantell, H.; Tolppanen, S.; Aarnio-Linnanvuori, E.; Lehtonen, A. Bicycle model on climate change education: Presenting and evaluating a model. Environ. Educ. Res. 2019, 25, 717-731. [CrossRef]

11. Monroe, M.C.; Plate, R.R.; Oxarart, A.; Bowers, A.; Chaves, W.A. Identifying effective climate change education strategies: A systematic review of the research. Environ. Educ. Res. 2017, 25, 791-812. [CrossRef]

12. Manzo, K. Beyond polar bears? Re-envisioning climate change. Meteorol. Appl. 2010, 17, 196-208. [CrossRef] 
13. Lee, J.J.; Ceyhan, P.; Jordan-Cooley, W.; Sung, W. GREENIFY: A real-world action game for climate change education. Simul. Gaming 2013, 44, 349-365. [CrossRef]

14. Deterding, S.; Dixon, D.; Khaled, R.; Nacke, L. From game design elements to gamefulness. In Proceedings of the 15th International Academic MindTrek Conference, New York, NY, USA, 29-30 September 2011; p. 9.

15. Werbach, K. (Re)Defining Gamification: A Process Approach; Springer Science and Business Media LLC: Berlin, Germany, 2014; Volume 8462, pp. 266-272.

16. Van Der Linden, S.; Maibach, E.; Leiserowitz, A. Improving Public Engagement with Climate Change. Perspect. Psychol. Sci. 2015, 10, 758-763. [CrossRef] [PubMed]

17. Grossberg, F.; Wolfson, M.; Mazur-Stommen, S.; Farley, K.; Nadel, S. Gamified Energy Efficiency Programs; American Council for Energy-Efficient Economy: Washington, DC, USA, 2015.

18. Chou, Y.K. Actionable Gamification: Beyond Points, Badges, and Leaderboards; Createspace Independent Publishing Platform: Milpitas, CA, USA, 2015.

19. Sailer, M.; Hense, J.U.; Mayr, S.K.; Mandl, H. How gamification motivates: An experimental study of the effects of specific game design elements on psychological need satisfaction. Comput. Hum. Behav. 2017, 69, 371-380. [CrossRef]

20. Conway, S. Zombification?: Gamification, motivation, and the user. J. Gaming Virtual Worlds 2014, 6, $129-141$. [CrossRef]

21. Willoughby, J.F.; Smith, H. Communication Strategies and New Media Platforms. Sci. Commun. 2016, 38, 535-545. [CrossRef]

22. Seaborn, K.; Fels, D.I. Gamification in theory and action: A survey. Int. J. Human-Computer Stud. 2015, 74, 14-31. [CrossRef]

23. Fogg, B.J. Persuasive technology. Ubiquity 2002, 2002, 2. [CrossRef]

24. Ouariachi, T.; Olvera-Lobo, M.-D.; Gutiérrez-Pérez, J.; Maibach, E. A framework for climate change engagement through video games. Environ. Educ. Res. 2018, 25, 701-716. [CrossRef]

25. Robson, C. Real World Research, 2nd ed.; Blackwell: Oxford, UK, 2002.

26. Saunders, M.; Lewis, P.; Thornhill, A. Research Methods for Business Students; Pearson Education: Edinburgh Gate, UK, 2015.

27. Mertens, D.M.; Hesse-Biber, S. Triangulation and Mixed Methods Research. J. Mix. Methods Res. 2012, 6, 75-79. [CrossRef]

28. Yeasmin, S.; Rahman, K.F. Triangulation Research Method as the Tool of Social Science Research. BUP J. 2012, 1, 154-163.

29. Consumption of Daily Electricity. Available online: https://saving.energypark.org.tw/ (accessed on 3 February 2019).

30. Oroeco. Available online: https://www.oroeco.com/ (accessed on 3 February 2019).

31. SaveOhno. Available online: https://www.saveohno.org/ (accessed on 3 February 2019).

32. Recyclebank-Turn Your Recycling into Seriously Sweet Rewards. Available online: https://www.recyclebank. com/ (accessed on 3 February 2019).

33. JouleBug. Sustainability App. Available online: https://joulebug.com/ (accessed on 3 February 2019).

34. My Little Plastic Footprint. Available online: https://mylittleplasticfootprint.org/ (accessed on 3 February 2019).

35. The Octalysis Tool. Available online: https://www.yukaichou.com/octalysis-tool/ (accessed on 3 February 2019).

36. Hardy, C.; Harley, B.; Phillips, R. Discourse analysis and content analysis: Two solitudes. Qual. Methods 2004, 2, 19-22.

37. SaveOhno.org-Gamified Platform for Climate Change Activism. Available online: https://www.kickstarter. com/projects/136597581/saveohnoorg?lang=es (accessed on 3 February 2019). 
38. Wu, J.S.; Lee, J.J. Climate change games as tools for education and engagement. Nat. Clim. Chang. 2015, 5, 413-418. [CrossRef]

39. Landers, R.N.; Auer, E.; Collmus, A.B.; Armstrong, M.B. Gamification Science, Its History and Future: Definitions and a Research Agenda. Simul. Gaming 2018, 49, 315-337. [CrossRef]

(C) 2020 by the authors. Licensee MDPI, Basel, Switzerland. This article is an open access article distributed under the terms and conditions of the Creative Commons Attribution (CC BY) license (http://creativecommons.org/licenses/by/4.0/). 